\title{
SPRUCE REGENERATION IN EASTERN CANADA AND NORTHEASTERN UNITED STATES
}

\author{
By M. WestVeld.
}

\section{INTRODUCTION}

T AM delighted to be with you at this time and consider it an honor to have been asked to present a paper at your annual meeting. It is with

a certain amount of trepidation, however, that I shall discuss regeneration of spruce stands from the standpoint of Canadian conditions since my experience in eastern Canada is relatively limited. I have had the opportunity, however, of visiting the spruce forests of central and southern Newfoundland and have seen something of New Brunswick, Nova Scotia and Quebec. In these travels I have been particularly impressed with the similarity of forest conditions in our northeastern states and the provinces of eastern Canada. My observations lead me to believe that with slight modifications many of the silvicultural measures advocated for spruce stands in our northeastern states can be applied with equally good results to a considerable portion of the spruce forests of eastern Canada. I trust then that you will bear with me while I briefly sketch the geologic history and forest types of the region to bring out these points of similarity and thus help to support and justify my contention.

\section{THE REGION}

The spruce regions of eastern Canada and northeastern United States have so many points of similarity that from a forester's viewpoint they may well be regarded as a single unit. Within this region lie two well recognized physiographic provinces, the great Laurentian area reaching down from the Hudson Bay into the Adirondacks of New York, and the New England Plateau coming up from the south and making a continuous province with New Brunswick, Nova Scotia, and that portion of Quebec lying north of the St. Lawrence. These two provinces are intimately associated with one another and to a large extent they share the same geologic and physiographic history.

\section{GEOLOGIC HISTORY}

A large part of the region was peneplained during the Jurassic and Cretaceous periods. This peneplain, consisting mostly of granites, gneisses and schists, was later uplifted, extensively disected through erosion and finally heavily glaciated. The region as a whole may be described as a vast plateau ranging in elevation from several hundred feet to two thousand feet above sea level. Typical examples of tablelands occur in the Hudson Bay region, the Labrador peninsula, southern New England and the upland sec- 

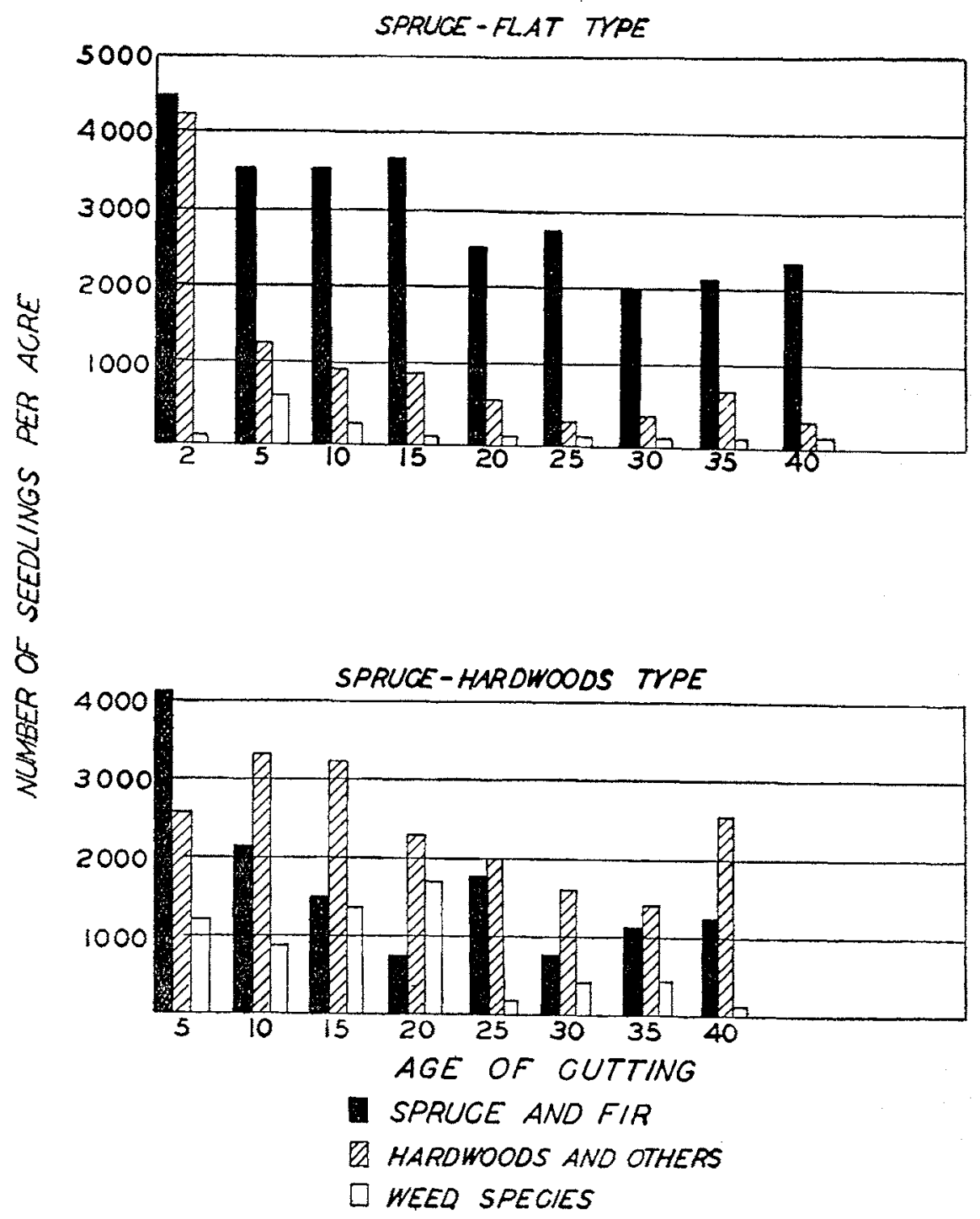

Fig. 1-Relation of composition and quantity to age of cutting for various forest types

tion of the western half of the Adirondacks. Yet there lie within the borders of this province important mountain groups such as the White and Green Mountains of New England, the Adirondacks of New York, the Laurentide Mountains bordering the St. Lawrence Valley, while in the Ungava peninsula we find the highest range of mountains in eastern North America. 
A comparatively recent geologic event which profoundly affected the topography was the invasion of the region by the Labradorean ice sheet from the north. In some cases ,as for example, in Labrador, portions of New, foundland, and exposed summits of certain mountain chains, the ice swept the surface practically clean of soil. Over the region as a whole, however, it dropped a mantle of heterogeneous debris, spreading it indiscriminately over hills, mountains, plains, and valleys, to varying depths, pushing it up in heaps and windrows, piling it in dams across the valleys, thus forming lakes and ponds, gouging out depressions to form swamps and muskegs. When at last the ice made its final retreat, the forests again moved northward, reclothing the shallow soils of far north and the steep slopes of the mountain ranges with coniferous stands of spruce and fir; the swamps and flats with spruce, fir, poplar, birch, cedar, tamarack, etc., the muskegs with black spruce; and the deeper soils on the ridges and benches in the lower portions of the region with spruce, fir, birch, beech, and maple. Glaciation, in other words, brought about changes in topography and soil conditions, the effect of which is expressed in the differences in the character of the forest growth in the wet soils of the swamps with its nearly pure coniferous growth as compared with mixed hard and softwood stands found in the drier, warmer soils of the better drained knolls and ridges.

\section{IMPORTANCE OF SPRUCE FORESTS}

The extensive tracts of forest that occur throughout this territory repre. sent one of its most valuable assets. The pulp and paper industry with its enormous investments has been built around this resource and the continued existence and prosperity of the industry rest on keeping the pulpwood lands of the region in a continuously productive condition. I am assuming in this discussion that throughout the region the aim of management is primarily the production of pulpwood. To accomplish this, cutting methods must be devised which will insure a full restocking of pulpwood reproduction on cutover lands, and silvicultural measures developed to bring the well stocked stands of young growth to fully stocked stands at maturity.

How can this objective be attained? This question strikes at the heart of one of the most important problems of the spruce region. Before attempting an answer, let us consider some of the elements that go to make up the problem.

\section{FOREST TYPES}

Within the spruce region occur several different forest types. The classification of these appears to be based partly on the character of the forest growth and partly on the physical conditions of the site. Since the kind of silvicultural practices to be applied depends to a large extent on the factors 


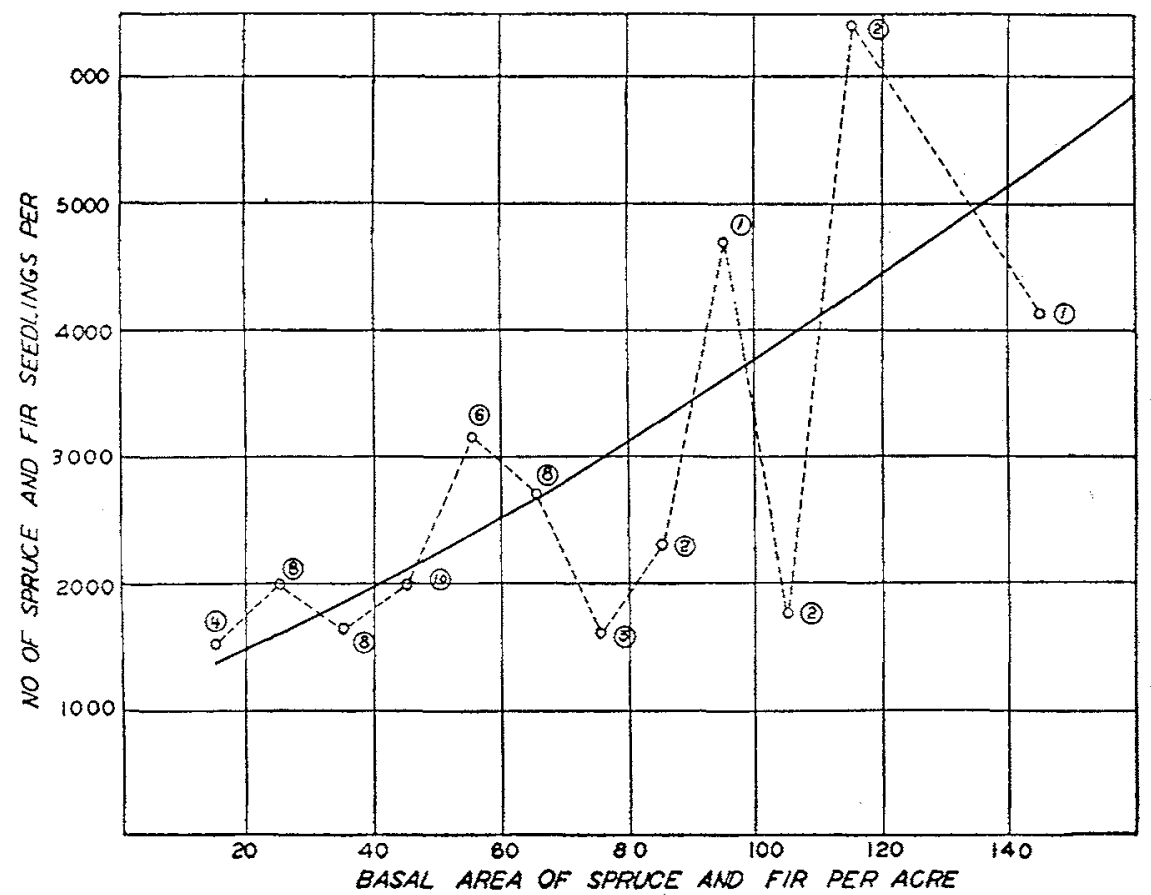

Fig. 2-Relationship of quantity of spruce and fir reproduction to quantity of spruce and fir in original stand.

that determine forest type, a description of the typical and important types will be a decided aid to a clear understanding of the problem. The follow, ing are the important recognized types of the region:-

1. SPRUCE SWAMP OR BOG. Low, wet areas supporting stands of black and red spruce, balsam, cedar, and tamarack. Advance reproduction is normally present.

2. SpRUCe Flat. This type occupies the low flats and knolls above the rivers and lakes. The soil is moist and shallow and supports heavy stands of spruce and fir. Red maple, yellow and paper birch may be present. Advance reproduction in this type is usually abundant.

3. BIRCH AND POPLAR. Although this type occurs throughout the region under a wide variety of site conditions, it is practically confined to areas which have been burned over. Birch and poplar, often with an admixture of red maple, are the chief species. Spruce and fir usually seed in and form an understory of conifers. Ordinarily a good understory of pulpwood species is present; however, all degrees of restocking are encountered.

4. Mixed SpRuce and Hardwoods. This type occupies the well-drained 
sitese of lower slopes and ridges. Spruce and fir are here found in mixture with the northern hardwoods, beech, birch, and sugar maple. In many instances yellow birch forms the dominant hardwood species. Advance reproduction of pulpwood species varies from a negligible amount to practically complete stocking.

5. SPRUCe Slope. The spruce slope type occupies the upper slopes of mountainous districts. Although the soils are shallow they support dense stands of spruce. Balsam fir, yellow and paper birch are usually present. Excellent reproduction is ordinarily present under the mature stands.

\section{SILVICULTURAL CONSIDERATIONS}

Unfortunately as yet we do not have available in this region accumulated data from long time experiments in methods of cutting spruce stands upon which sound silvicultural systems for the various spruce types should be based. Eventually such data will be available. In the absence of data of this type we undertook an extensive study of reproduction conditions in both cut and uncut stands. We obtained a wide representation of age cuttings, as to age, stand composition, forest types and site conditions. Particular at. tention was paid to factors governing regeneration under these varying conditions. A compilation and analysis of the data have established many substantial correlations which have been of great value in developing a practical scheme of silviculture for spruce stands. I shall present some of these fundamental facts and show the part they play in the formulation of silvicultural practices for spruce forests.

1. Reproduction Conditions. In the first place, throughout the major portion of the region, growing conditions are particularly favorable for abundant forest growth. This is reflected not only in the character of the virgin growth but in the general abundance of advance reproduction, both in old growth stands and in cut-over areas, regardless of the severity of cutting. In young, even-aged stands characterized by a dense continuous overhead canopy, advance reproduction may be scarce or entirely lacking. Cut-over areas supporting abundant reproduction are in nearly all instances those on which the bulk of the advance growth was present in the original stand. Where this advance growth is absent at the time of cutting subsequent restocking with conifers progresses at an extremely slow pace or fails completely.

The quantity of reproduction varies with forest type, spruceslope show. ing the largest number; spruce-flat next; and mixed spruce-hardwoods the least. The relative abundance of hardwood and conifer reproduction on the spruce-flat and spruce-hardwood types, the two types of greatest extent and importance in the region, is indicated in Figure I. The figure indicates the tendency of spruce tlats to produce large numbers of spruce and fir seedlings 


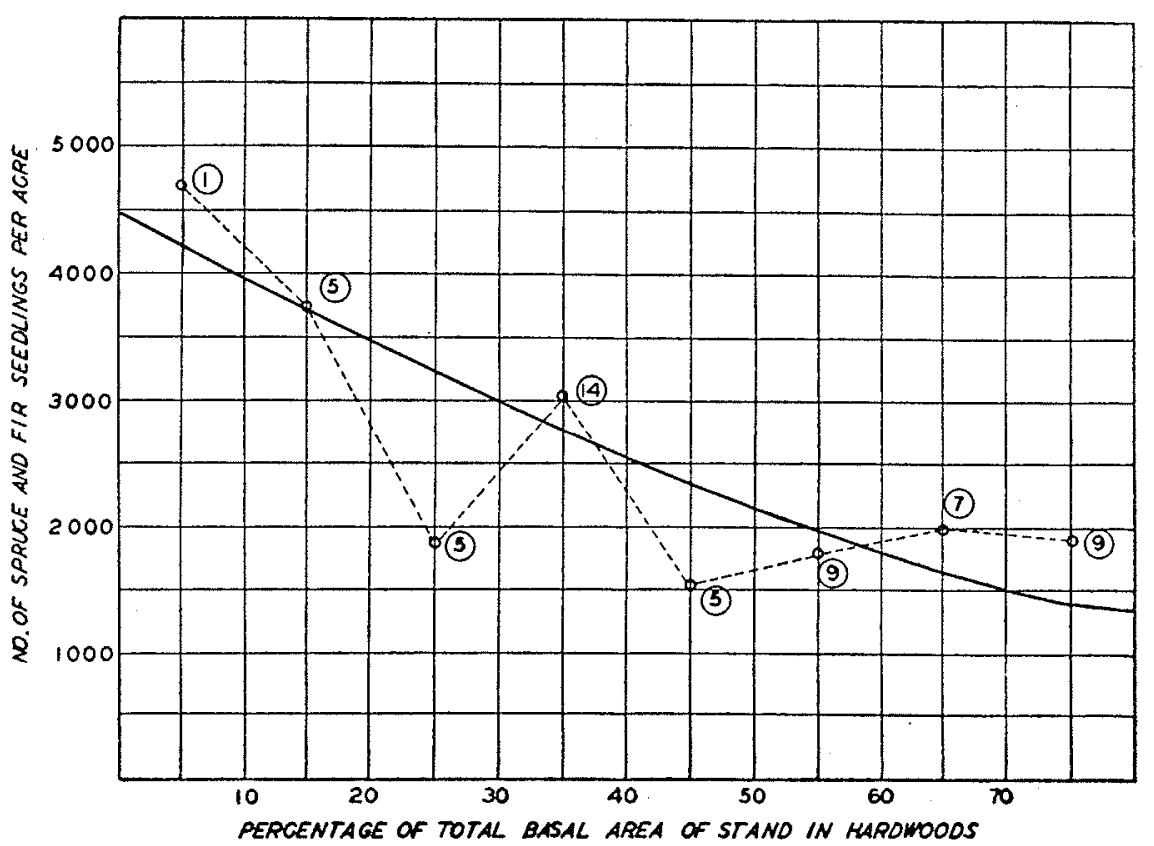

Fig. 3-Relationship of quantity of spruce and fir reproduction to hardwoods in original stand.

and relatively small numbers of hardwoods. In the spruce-hardwoods type fewer seedlings of pulpwood species are produced, whereas hardwoods apparently find no difficulty in establishing themselves in large numbers. In general the largest number of spruce and fir seedlings were found on areas which had originally supported the largest volumes of spruce and fir, as for instance, in pure stands of conifers encountered in the spruce flats, swamps, and slopes. See Figure II. On the other hand where hardwood representation is higher the quantity of coniferous reproduction is correspondingly low as indicated in Figure III.

Man's interference as a factor affecting the quantity of reproduction must not be overlooked. The quantity of young growth in spruce stands is greatly reduced during logging operations. Studies show losses from this source ranging from 20 per cent to as high as 40 per cent., with highest losses occurring in the 2 to 5 foot height class. To this must be added the loss resulting from the windrowing of dense slash on reproduction. Dense softwood slash not only crushes and kills the advance reproduction beneath it but effectually prevents the establishment of new reproduction on areas occupied by it for a period of from 15 to 20 years. Loss from these sources becomes a particularly serious matter in stands containing an understocking of reproduction. 
2. Site Conditions. Site conditions as reflected particularly in soil composition and soil moisture exercise a marked effect on the character of the stand. The study showed that by far the greatest number and proportion of conifers are ordinarily found in the shallow or poorly drained soils such as are found in spruce flats and swamps. Good drainage combined with soils of depth and fertility, characteristic more or less of mixed spruce hardwood lands, result in increased proportion of hardwoods and a decrease in the number of spruce and fir. The quantity of softwood reproduction and the reduced importance of hardwoods in the spruce flat type is in strong contrast with the general abundance of hardwoods and relatively low representation of pulpwood species in the spruce hardwoods type, as clearly brought out by Figure I.

Preponderance of hardwoods and small representation of spruce and fir in the well drained soils is not due to the fact that these sites are inimical to the development of conifers but to the severe competition set up by hardwoods which succeed in establishing themselves at the expense of spruce. On the other hand the high representation of conifers in the spruce-flat type may be attributed to the ability of these species to thrive in soils not particularly suited to the needs of their hardwood competitors. As a rule the greater the representation of hardwoods, the greater are the difficulties encountered in the renewal of a pulpwood crop. More difficulty in this respect is experienced where the predominating hardwoods are beech and sugar maple than where they consist mainly of birches and popple.

3. Competing Growth. The condition of cut-over lands and their later development is an important factor influencing the choice of cultural measures to be employed. Clear cutting of pulpwood in pure spruce and fir stands leaves such areas nearly devoid of trees. The same type of cutting, however, in mixed hard and soft wood stands leaves varying numbers of hardwoods of all sizes to comprise the residual stand. The advance reproduction of spruce and fir which is normally present under the old growth stands ready to spring up following the removal of the old trees. Where no competitive growth is present the young stand of conifers develops rapidly into pulpwood size. On extensive areas, however, it is an open question whether or not the young stand will attain merchantability owing first:-to the effect of shade and interference of the large residual hardwood crowns on the young spruce and fir growing beneath, and secondly:-to young stands of fast growing hardwoods and weed species which often spring up in dense masses following cutting and compete strenuously with the young conifers for the possession of the ground. Studies, however, show that freeing of young conifers from the overstory of residual hardwoods can be economically accomplished through selective girdling of hardwoods. To relieve the young stand from excessive competition offered by young hardwoods, weeding 


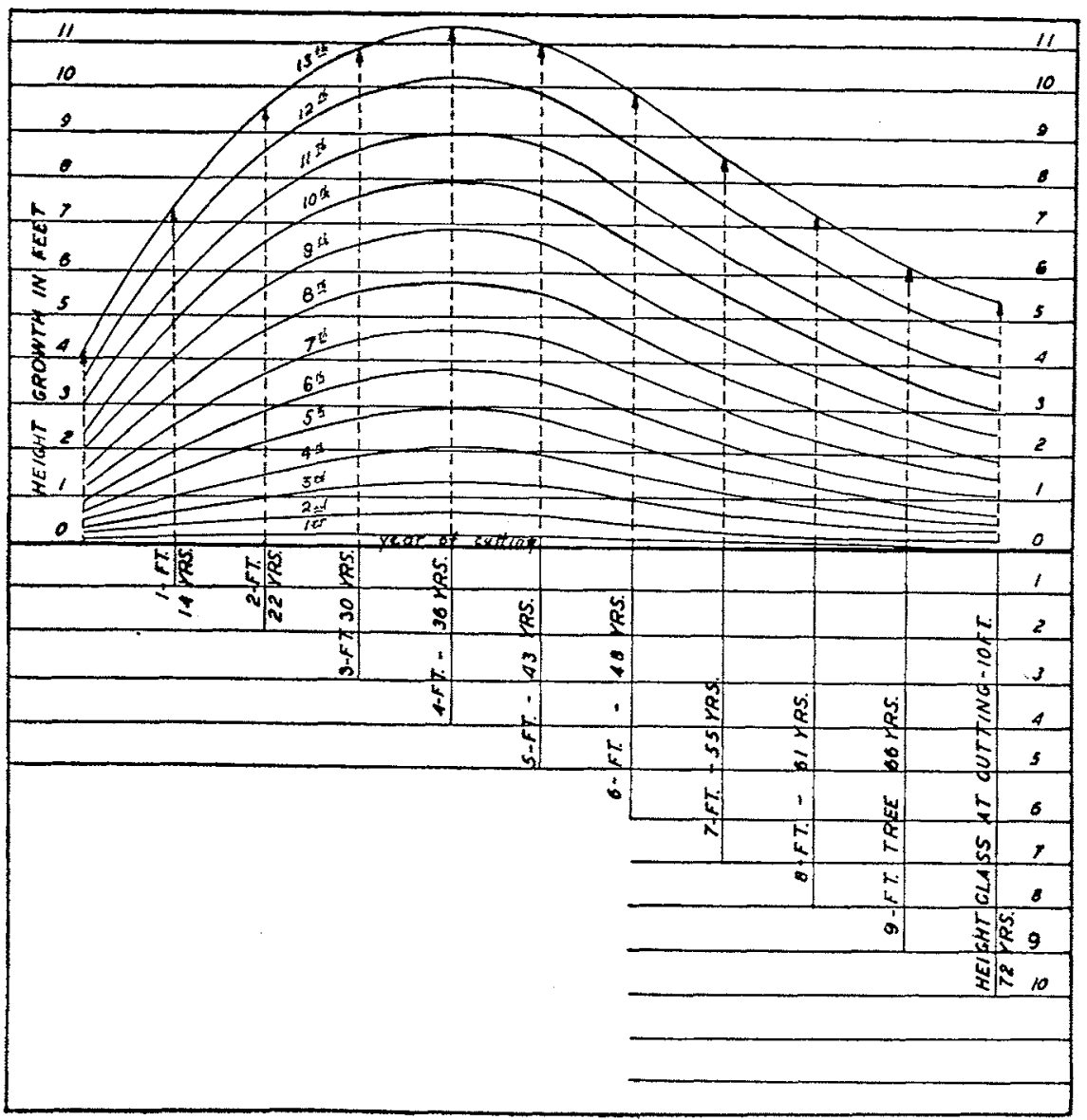

Fig. 4-Chart showing current annulal growth for thirteen years following cutting for red spruce trees of various heights at time of cutting; and relationship of height to age. Seedlings and saplings suppressed at time of cuting and released through cutting. Original canopy dense. All trees now dominant.

or release cuttings in which young hardwoods are cut back must be resorted to. Competitive hardwoods growth constitutes the most disturbing single factor operating to prevent the final establishment and development of spruce and fir.

The study also served to emphasize the importance of the difference in rate of growth of different sized pulpwood seedlings following cutting. Its importance lies in the corresponding advantage or disadvantage in meeting competition. The mere presence of advance reproduction in itself is no in- 
surance that it will ultimately form a portion of the next timber crop. As I stated previously, following cutting aggressive hardwoods quickly become established and through rapid height growth often succeed in overtopping the slower growing conifers. It is important, therefore, that the advance reproduction be of sufficient height to maintain its ascendency over the incoming hardwoods.

Analysis of spruce seedlings and saplings brought out great differences in their capacity for height growth following cutting. That seedlings between 3 and 5 feet in height at the time of cutting put on the most rapid height growth is clearly shown in Figure IV. It is this size class then that stands the best chance of competing successfully with invading hardwood growth. It will be recalled that it is this size class that suffered the heaviest loss through logging operations. Seedlings below 2 feet in height are very likely to be choked out of the stand by vigorous young hardwoods as indicated in Figure $\mathrm{V}$. The slow growth of spruce under the mature stand as well as the remarkable capacity it possesses for recovery after long periods of suppres. sion is also indicated in Figure IV.

\section{BASIC CONCLUSIONS}

An analysis of the facts brought out by the study leads to several important conclusions which serve to form the frame work of the silvicultural measures devised for various forest type conditions. These conclusions may be briefly summarized as follows:

Because of the great economic importance of spruce to the region it is essential to maintain potential pulpwood lands in the pulpwood producing class. For the region as a whole this does not represent a difficult silvi, cultural problem for over much of the region we are not faced with an intricate problem in regeneration. The development of silvicultural systems of cutting for the purpose of establishing pulpwood reproduction represents a problem of secondary importance in the region, though I do not mean to imply that this will be true indefinitely. In most instances nature provides the nucleus of the new crop in the form of advance reproduction in the old mature stand. The major problem then centers around the formulation of cultural practices for spruce lands which will protect and develop the already existing stands of reproduction to full timber crops at maturity.

Cognizance should be taken of the fact that certain stands, due to site and reproduction conditions, lend themselves more readily to the management of spruce and fir than do others. For instance, spruce and fir reproduction in the spruce-flat type experiences much less difficulty in maintaining its position with the contemporary hardwood growth than in the spruce hardwoods. Even the application of intensive forestry measures may fail to keep 


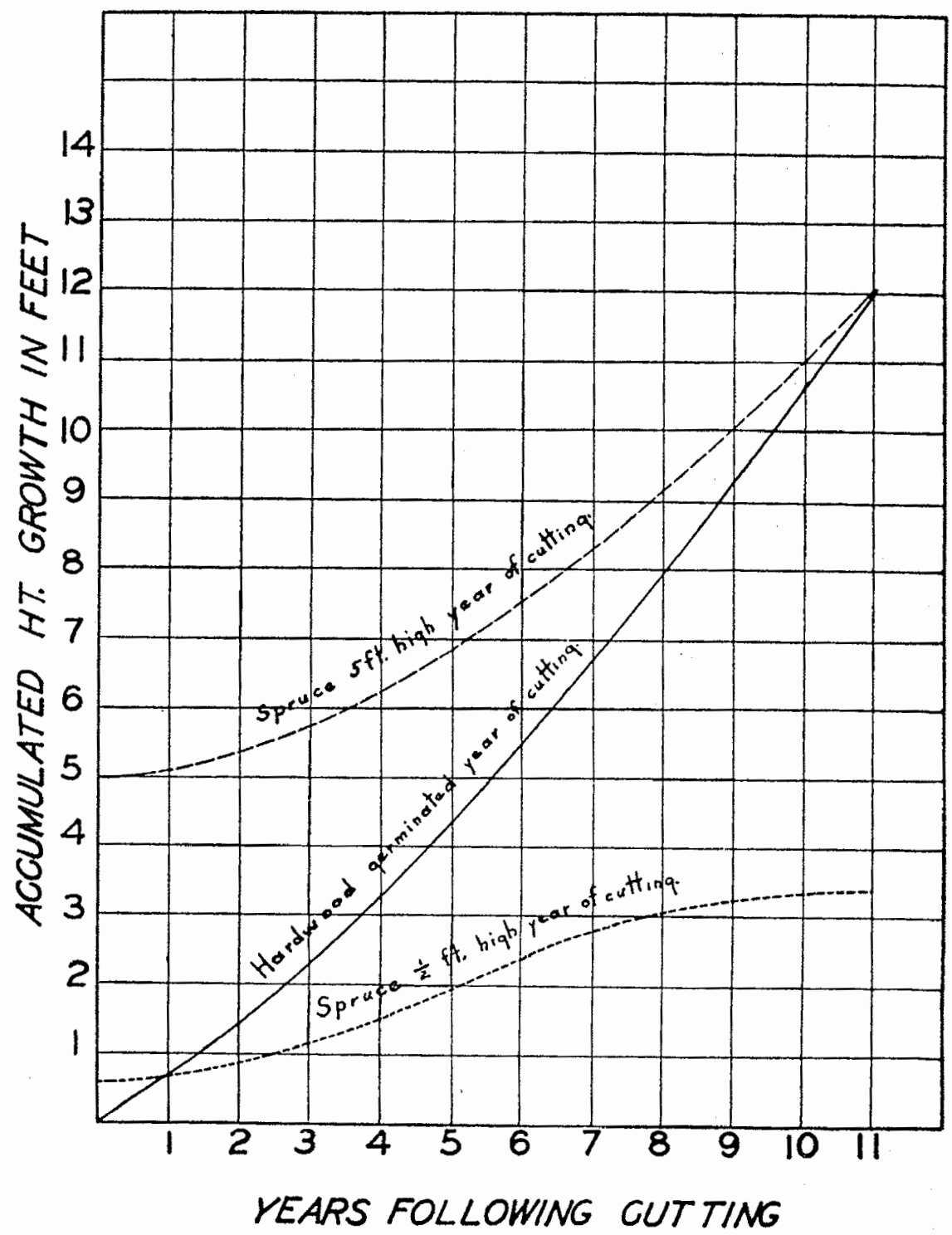

Fig. 5-Comparative growth rate of seedlings of different sizes following cutting

in the pulpwood producing class certain sites in the spruce region which are distinctly favorable to hardwood production without excessive cost.

Data clearly point to the necessity of securing early regeneration of pulp. wood species. The presence or absence of this advance reproduction deter- 
mines in many instances the success or failure of pulpwood species to form an integral part of the succeeding stand. Cutting should be so graduated as to permit seedlings to come in and reach 2 to 5 feet in height before the protective cover of the main timber stand is removed. Aside from intensive cultural treatment of stands, nothing is so effective in attaining the purposes of management as regulation of the time of cutting. The key to the silviculture of spruce stands lies mainly in taking advantage of such favorable factors as nature has already placed at man's disposal.

\section{CUTTING METHODS}

In the application of silvicultural practices it is essential to recognize sharper lines of distinction than those afforded by type differentiations. Each condition within the type must be recognized and treated in accordance with its requirements. This line of procedure is particularly desirable in the spruce hardwoods type where there is the widest variation in stand composition, reproduction, and soil conditions. Similar variation also occurs in spruce flats but usually to a less degree. Variations occur in the spruce swamp and spruce slope types as well but on the whole these are much more uniform. I shall discuss silvicultural methods under two headings: (1) pure softwood stands and (2) mixed hardwood and softwood stands, since they represent two distinct sets of conditions.

\section{PURE SOFTWOOD STANDS}

In pure or nearly pure stands of spruce and fir, such as often occurs in spruce swamps, spruce slope and not uncommonly, in the spruce flat type, containing a full stocking of advance reproduction, clear cutting of all merchantable material is recommended. This obviates windthrow and removes the overhead canopy, thus permitting rapid development of the new stand already established. In cases where hardwoods gain dominance, weeding should be employed.

Where advance reproduction is lacking a shelterwood system may be practiced in which one-third to one-half of the trees are removed, opening up the stand uniformly. This creates favorable conditions for the establishment of spruce and fir reproduction, after which the remainder of the stand with its increased growth may be logged.

\section{MIXED HARDWOOD AND SOFTWOOD STANDS}

Where advance reproduction of pulpwood species in mixed stands is adequate all merchantable softwoods and hardwoods should be cut. The scanty crown canopy left following cutting has little adverse effect on the advance growth. Where yellow birch is the predominating hardwood, competition from encroaching hardwood growth is less keen than in stands where beech and hard maple are the dominating hardwoods. To prevent reproduction from 
being crowded out by invading brush growth, cutting should be made when reproduction has attained an average height of two feet in the yellow birchspruce-sub-type and approximately four feet in the sugar maple-spruce-subtype. Where conifers fail to gain dominance, girdling and weeding of hard. woods must be resorted to.

Where advance reproduction of conifers is lacking, conversion to pulp. wood species can be accomplished only through clear cutting and planting, followed later by cleanings. Such stands should be managed primarily with the idea of developing the young growth already established, the amount of softwoods being attained thereby being a secondary consideration. This can be accomplished in even-aged stands through clear cutting and in all-aged stands through selection cutting, removing the older age classes and holding the younger for increased increment and quality growth.

\section{SLASH DISPOSAL}

The long period that coniferous slash constitutes a menace to reproduction makes it justifiable to spend money for its disposal. A scheme of slash disposal which should appeal to the average operator is one of partial disposal in which only dense masses of slash are burned as well as slash on particularly hazardous areas along roads and railroads. Such a method, supplemented by an intensive patrol, should provide adequate protection for cut-over lands.

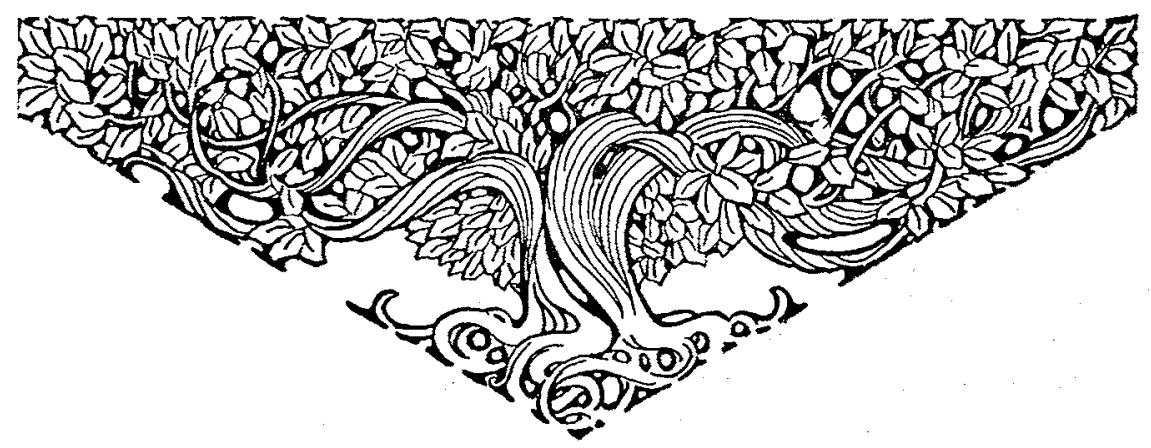

